\title{
HETEROTOPIA E SUBJETIVIDADE: OS EFEITOS DA REPRESENTAÇÃO NACIONAL FRANCESA SOBRE O SUJEITO-ALUNO DE FRANCÊS
}

\author{
(Heterotopy and subjectivity: the effects of the french national \\ representation on the subject of french student)
}

\author{
Andréa Zíngara Miranda ${ }^{1}$ \\ Pedro Navarro (UEM) ${ }^{2}$ \\ (Universidade Estadual de Maringá - UEM)
}

\begin{abstract}
The subjectivity of education subjects, or rather, the students of French at the Center of Modern Foreign Languages (CELEM) is discussed. Questions, asked to subjects on their impressions on French language and culture, were answered by stereotyped replies and showed that they gave more value to that culture than they gave to theirs. Heterotopy and subjectivity concepts, foregrounded on Michel Foucault's perspective, were consequently introduced. Current analysis suggested that there was a very close relationship between the effects of French national representation on the subjects and the "other place" constructed in the discourses under investigation.
\end{abstract}

Keywords: Heterotopy; subjectivity; national representation.

\section{RESUMO}

Este artigo propõe uma reflexão acerca da subjetividade do sujeito da educação, mais precisamente o estudante de língua francesa do Centro de Línguas Estrangeiras Modernas (CELEM). A partir de questões propostas a esses sujeitos referentes às suas impressões sobre a língua e a cultura francesas, foram constatadas representações estereotipadas dessa cultura, o que indica que esse sujeito supervaloriza essa cultura em detrimento da sua. Para tanto, mobilizaram-se conceitos de heterotopia e de subjetividade,

1. Mestranda do Programa de Pós-Graduação em Letras da Universidade Estadual de Maringá e pesquisadora do Grupo de Estudos Foucaultianos (GEF).

2. Professor do Departamento de Letras e do Programa de Pós-Graduação em Letras da Universidade Estadual de Maringá. Líder do Grupo de Estudos Foucaultianos (GEF). 
ambos com base na perspectiva do filósofo Michel Foucault. O estudo conclui haver uma estreita relação entre os efeitos da representação nacional francesa sobre o aluno e o lugar-outro construído nos discursos sob análise. Palavras-chave: heterotopia; subjetividade; representação nacional.

\section{Introdução}

A proposta deste texto é fazer uma discussão sobre o sujeito da educação à luz de um viés discursivo que considera a relação entre língua e história na produção de subjetividades. Essa discussão percorre um caminho teórico que passa pelas reflexões de Michel Foucault (1979, 1984, 1997, 2000, 2006) sobre saber e poder, estética da existência, subjetivação, heterotopia e subjetividade. O diálogo entre esses conceitos, pensado a partir de determinadas representações estereotipadas da língua e da cultura francesas, foi suscitado a partir de algumas questões propostas aos alunos do Centro de Línguas Estrangeiras Modernas de Apucarana-Pr sobre suas impressões da língua e da cultura francesas.

O fio condutor destas reflexões traça o seguinte percurso: realizase, em um primeiro momento, um gesto de leitura das respostas que esses sujeitos deram a essas questões, compreendendo-as como enunciados; com base nisso, discute-se a relação saber e poder que se manifesta nesses enunciados; na sequência, é realizada uma discussão sobre a estética da existência e da subjetivação e, por último, é feita uma reflexão sobre a relação entre heterotopia e subjetividade, atentando, com isso, para a constituição e circulação de determinada representação nacional francesa.

\section{Os efeitos da representação nacional sobre o sujeito- aluno}

No intuito de estudar os poderes e saberes na sociedade contemporânea, o filósofo Michel Foucault não se preocupou em construir uma teoria do discurso, entretanto, ao elaborar o método 
arqueogenealógico, contribuiu para que analistas de discursos obtivessem "ferramentas” para suas análises, já que nele são contempladas formas de analisar enunciados.

Importa ressaltar que, por enunciado, considera-se, na esteira de Foucault, aquilo que foi efetivamente dito pelos alunos entrevistados. Nesse sentido, as impressões por eles enunciadas inserem-se em um feixe de relações que constitui a formação discursiva que congrega um dado arquivo sobre a língua e a cultura francesa. Sendo um átomo do discurso, como concebe Foucault, o enunciado é a menor unidade de uma formação discursiva, e a sua descrição, tal como é feita neste momento, pode dar visibilidade aos saberes que organizam a prática pedagógica e a relação entre os estudantes de francês. É sob esse mirante, portanto, que se tomam os dizeres dos entrevistados como enunciados.

A perspectiva aqui assumida é a de que o sujeito é constituído no e pelo discurso, pois ele não pré-existe à linguagem. Consoante a essa ideia, acredita-se existir uma relação intrínseca entre as práticas discursivas sobre a França e a subjetividade do estudante de língua francesa, já que o discurso é algo mais que um conjunto de significantes e produz saberes, como ensina o autor, ao afirmar que:

gostaria de mostrar que o discurso não é uma estreita superfície de contato, ou de confronto, entre uma realidade e uma língua, o intrincamento entre um léxico e uma experiência; (...). Certamente os discursos são feitos de signos; mas o que fazem é mais que utilizar esses signos para designar coisas. É esse mais que os tornam irredutíveis à língua e ao ato da fala. É esse mais que é preciso fazer aparecer e que é preciso descrever (FOUCAULT, 1997: 55-6).

Nesse viés, o autor opera com a questão da emergência dos discursos, isto é, o porquê do surgimento de determinados enunciados e não de outros em dada sociedade e época. E o surgimento do discurso decorre tanto do feixe de relações que permite dizer as coisas de uma forma e não de outra quanto dos efeitos de poder que permeiam os discursos. Saber e poder são, portanto, as duas instâncias que dão suporte para a constituição e para a formulação 
dos enunciados pelos quais os alunos se manifestaram diante das questões propostas.

$\mathrm{Na}$ tarefa de compreender a materialização das representações anteriormente anunciadas, foi realizado um gesto de descriçãointerpretação dos documentos (enunciados) aqui apreendidos como monumentos, já que se considera a articulação entre linguagem e história. Foram descritos sessenta enunciados, dos quais dez são analisados neste texto. É importante salientar que os sujeitos que responderam às questões formuladas são alunos da rede pública dos ensinos fundamental e médio ou membros da comunidade fora de idade escolar, que é o requisito básico para se inscrever no CELEM. Dentre oito questões, foram selecionadas três que respondem ao objetivo principal deste texto: (1) o que o motivou a se inscrever no curso de língua francesa?, (2) qual a imagem que você tem da França e dos Franceses? e (3) como você se vê frente à França?

Como observa Bauman (2005: 48), a identidade se movimenta na ambivalência unidade versus diferença. Assim, os enunciados analisados manifestam que esses sujeitos apresentam sua identidade fragmentada, como se quisessem para si o que vêem no outro. Daí a importância, na atualidade, de se falar tanto em identidade, como pondera Navarro, para quem "estudos recentes, advindos dos mais diferentes campos das ciências humanas, mostram a angústia da nossa sociedade para entender 'quem somos nós'” (Navarro, 2008a: 89).

Nas sequências discursivas, percebe-se um sentimento de inferioridade do sujeito frente ao Outro quando demonstra ter internalizado um discurso homogêneo e sempre positivo sobre o país. Mais que expressar o que acredita ser o outro acaba por expressar seu conflito com a própria identidade, uma vez que vê a si mesmo.

Essas observações podem ser contempladas nos enunciados que se seguem em respostas às três principais questões. É importante lembrar que a leitura interpretativa foi antes uma tentativa de localizar ordens ou configurações dos saberes para delas fazer uma experiência crítica, como orientam os estudos de Foucault. Logo, não se propõe, neste texto, uma história do referente a qual indagaria o que foi 
realmente "tal coisa", mas se buscou compreender o que possibilitou que algo fosse dito.

Sobre o que os teria motivado a se inscrever no curso de língua francesa, a pesquisa obteve os seguintes enunciados:

\section{E1}

Primeiramente por curiosidade porque todo mundo fala que é lindo e também pra ter um diferencial no currículo.

\section{E2}

É uma língua diferente e muito bonita e depois todo mundo já estuda inglês.

E3

Sempre tive vontade de estudar francês porque acho uma língua charmosa e como apareceu esta oportunidade eu aproveitei. Já sei inglês, assim meu currículo terá uma língua a mais.

E4

Além do interesse em conhecer uma língua diferente, chique, o francês se torna importante em meu trabalho de conclusão de curso de Moda.

A leitura interpretativa desses enunciados permite dizer, de uma maneira mais geral, que a língua aparece como utilitarista, já que seria um diferencial, enriquecendo o curriculum em um mundo cada vez mais globalizado. No entanto, a idealização dessa língua, construída e repetida por uma memória político-social dominante, atravessa os enunciados desses sujeitos, sendo textualizada pelo uso dos adjetivos lindo, bonita, charmosa e chique. Apropriando-se de um pronome indefinido, os sujeitos dos enunciados categorizam a língua como sendo de fato bela ("todo mundo fala que é lindo") e até comparam-na com o inglês, que faz parte da matriz curricular ("todo mundo já estuda inglês”), logo é obrigatório, diferentemente do francês. A língua, nessa perspectiva, é relacionada ao belo e à não-obrigatoriedade, fatores que, no mínimo, parecem contribuir para um estudo mais prazeroso. 
Quando questionados a propósito da imagem sobre a França e dos Franceses, as respostas deles foram quase idênticas, o que indica uma regularidade nessa produção discursiva. Da série enunciativa analisada na pesquisa, destacam-se dois enunciados representativos dessa posição de sujeito:

\section{E5}

País do romantismo, da beleza, da luz...berço da cultura, as pessoas são lindas e fazem 'biquinho' pra falar, um charme!.

\section{E6}

Me vem à cabeça um lugar organizado, rico, com muita cultura em relação ao nosso, restaurantes chiques, mas parece que os franceses não tomam banho, por isso os perfumes são bons.

Nas impressões do aluno sobre o país e sobre seu povo, percebese que as representações caminham sempre para a mesma direção, ou seja, "o belo"; o país seria belo como sua língua e seu povo. Não obstante o enunciado de E6 manifestar uma imagem depreciativa e também cristalizada ("mas parece que os franceses não tomam banho"), o sujeito não admira menos o país e mesmo os franceses em virtude disso.

Os estudantes do CELEM de Apucarana, a maioria adolescentes, nunca foram à França, logo seus discursos são constituídos a partir das imagens do país mostradas em revistas, em imagens de televisão ou em livros didáticos de história e de língua francesa que circulam no espaço escolar. As imagens normalmente mostram o que o país tem de melhor, sua cultura com seus belos museus e meios de transportes de última geração. Raramente, há estrangeiros, com exceção dos turistas; logo, mostra-se um país de um só povo e, como pretendeu a Revolução Francesa, de uma só língua. Daí a ideia de país organizado.

Ao expressar como se veem frente à França, apenas dois dos sujeitos entrevistados fugiram ao senso comum: 


\section{E7}

Como brasileiro eu sou muito a favor da cultura alemã e a americana. O brasileiro é uma mistura de todas as culturas ocidentais, odeio a culinária e a música francesas, vejo uma sociedade conservadora, mas admiro sua economia. Acho ridículo essa cultura de pratos típicos, de gastronomia, acho interessante museus franceses.

\section{E8}

Em certas coisas, a cultura brasileira aparenta ser 'pobre' ou oposta à européia. Como brasileira me sinto equiparada culturalmente a qualquer país, já que para mim o que deve ser levado em conta não é a cultura de um país, mas sim como cada pessoa representa e se interessa por sua cultura.

\section{E9}

Lá não tem desemprego porque é um país de primeiro mundo. As pessoas têm acesso a tudo. Eles têm um ótimo padrão de vida. Então me vejo em desigualdade.

\section{E10}

Não dá pra comparar, somos de terceiro mundo. Eu como brasileiro me vejo em desvantagem porque aqui as pessoas não são educadas como lá, não têm acesso à escola, nossa economia não é como a deles, lá os cidadãos são respeitados.

Nos enunciados sete e oito os sujeitos parecem não se mostrar intimidados frente à outra cultura, ressaltando os valores de sua terra natal. No entanto, no enunciado sete o aluno parece dividido, demonstrando certo desprezo, mas também admiração.

Esses enunciados autorizam pensar, de um modo mais geral, que as imagens do país giram em torno da beleza e do refinamento. Esses sujeitos assumem certa representação da França, segundo a qual é um país modelo, onde não há fome, pobreza, não há desemprego, não há variedade linguística ou climática. É, enfim, o país de um povo e de uma cultura homogêneos, o ideal de civilização. Um contraste 
que vem de encontro com seu país de origem, que não tem aquilo que ele vê no outro.

A imagem do aluno sobre os franceses repisa e reforça a memória discursiva de que lá as pessoas são belas e educadas, bem sucedidas profissionalmente e intelectuais. A economia do país asseguraria a educação e o emprego. É importante ressaltar, entretanto, que esse imaginário é herança de um discurso construído não só pela mídia, mas pelos próprios livros didáticos de língua francesa com os quais os sujeitos do ensino e aprendizagem desse idioma mantêm contato. Os discursos que circulam por esses meios de comunicação, longe de mostrar um país de diversidade cultural, sugerem a imagem de um país unificado, que luta por manter sua identidade em meio à globalização.

A língua e a cultura francesas são vinculadas a uma memória de língua "refinada". O sujeito que se afasta da língua dos intelectuais afasta-se da condição de ter cultura. As sequências discursivas aqui analisadas podem tomar forma de documentos, se apreendidas como verdade, e a consequência disso é a perpetuação de certo passado idealizado, mas, uma vez interpretadas historicamente, o que se vê é a substituição da História com "H" maiúsculo pela história com "h"minúsculo, nos moldes propostos pela chamada Nova História, perspectiva segundo a qual havendo vestígios da passagem do homem, sua marca de vida e de inteligência, a história ali se deixa escrever (DOSSE, 2001; LE GOFF, 1998).

Dito de outro modo, essa possibilidade de análise de fatos discursivos pode se somar a uma forma de fazer história, a qual elege aquilo que os sujeitos dizem. Como postula Foucault (2005), é possível fazer, por meio dos enunciados efetivamente ditos, uma história do tipo serial, que, ao invés de privilegiar objetos gerais e constituídos por antecipação, como, por exemplo, a revolução industrial, "define seu objeto a partir de um conjunto de documentos dos quais dispõe" (FOUCAULT, 2005, p. 290). O exemplo dos arquivos do porto de Sevilha, no século XVI, dado pelo autor, ilustra esse tipo de estudo. 


\section{Relações Saber-Poder}

Ao se propor como objeto de estudo a subjetividade, tornase necessário trazer à tona aquilo que culminaria na constituição do sujeito, isto é, as relações saber-poder.

A obra de Michel Foucault tratou de temas diversos, no entanto pode ser classificada em três momentos, como observou Navarro ao dizer que:

A obra de Michel Foucault pode ser classificada em três momentos que, embora pareçam distintos, se imbricam: ser-saber, ser-poder e ser-si, nos quais analisa respectivamente, a constituição dos saberes na sociedade, as formas por meio das quais o poder é exercido sobre os sujeitos e a experiência do indivíduo com a sua sexualidade (NAVARRO, 2008b: 59).

Nesse âmbito, parece oportuno compreender a escola como um dispositivo que produz subjetividades, uma vez que a escola é um espaço de enunciação no qual os saberes se instauram juntamente com o poder. Para Gore (2008: 10), todos os discursos podem ser vistos como regimes de verdade, se se considera que a verdade e o poder estão ligados em uma relação circular. Dessa forma, o cotidiano escolar torna-se, também, um dispositivo de poder ao ser palco de determinados discursos. Enfim, como analisa Foucault, não se trata de libertar a verdade do poder, já que a própria verdade é poder, mas de desvincular o poder da verdade das formas de hegemonia sejam sociais, econômicas, culturais, no interior das quais ela funciona.

Isso autoriza pensar nas práticas discursivas concernentes à língua e à cultura francesas veiculadas pela mídia, pelos livros didáticos e pelos professores. Em tais práticas a França aparece como o país das vitórias, dos intelectuais, da unidade linguística (país de um só povo e onde se fala a mesma língua, sem dialetos, regionalismos etc.); nessa relação de um saber sobre a França com o poder das práticas discursivas sobre o sujeito, instaura-se uma verdade, isto é, o sujeitoaluno apreende esses discursos como únicos e verdadeiros. 
O estudante é atravessado, como assegurado pelos efeitos da memória coletiva, por discursos que retomam outros preexistentes, discursos que reforçam o mito do país da revolução intelectual, como se pode observar nas sequências enunciativas de E5 "país do romantismo, da beleza, da luz...berço da cultura", de E6 "me vem à cabeça um lugar organizado, rico, com muita cultura em relação ao nosso" e de E10 "[...] porque aqui as pessoas não são educadas como lá, não têm acesso à escola, nossa economia não é como a deles, lá os cidadãos são respeitados". Os sujeitos envolvidos com essa cultura e essa língua relacionam essas práticas discursivas com uma memória social fazendo reviver um tempo em que os padrões de vida franceses eram imitados, sobretudo no século XIX; falar francês era sinônimo de sofisticação e de refinamento intelectual; ler em francês significava ter acesso à cultura, reafirmando a identidade nacional já cristalizada. Apóiam-se, enfim, em uma memória social operada por uma imagem que, segundo Davallon (1999: 27), representa a realidade, mas pode também conservar a força das relações sociais.

As práticas discursivas veiculadas pela mídia, pelos livros didáticos e pelos professores produzem saberes ao mesmo tempo em que exercem poder e conduzem comportamentos. $\mathrm{O}$ sujeito da educação, por sua vez, estando vinculado a uma instituição, nesse caso o CELEM, torna-se sujeito dessa relação saber-poder, constituindo sua subjetividade. Lembrando que os professores, eles mesmos, também são submetidos a essas práticas, uma vez que eles não são origem de seus discursos.

\section{O Ser-Si: A Estética da Existência e a Subjetivação}

Destacou-se, na seção anterior, que a obra de Michel Foucault é marcada por três momentos que estão imbricados, pois o sujeito nunca deixou de ser seu objeto, como afirma em sua introdução ao Uso dos Prazeres: 
O projeto era, portanto, o de uma história da sexualidade enquanto experiência - se entendemos por experiência a correlação, numa cultura, entre campos de saber, tipos de normatividade e formas de subjetividade. (FOUCAULT, 1984: 10)

O autor não propõe uma história da sexualidade entendida como concepções do desejo ou da libido, a atenção é voltada às práticas pelas quais os indivíduos foram levados a prestar atenção em si, a se reconhecerem e a se confessarem como sujeito de desejo, para nesse desejo descobrir a verdade de seu ser. Assim, lançando-se em uma história da verdade, Foucault afirma que:

ficou claro que empreender essa genealogia me afastava muito de meu projeto primitivo (...) afinal de contas, aquilo a que me atenho - a que me ative desde tantos anos - é a tarefa de evidenciar alguns elementos que possam servir para uma história da verdade. Uma história que não seria aquela do que poderia haver de verdadeiro nos conhecimentos; mas uma análise dos 'jogos de verdade', dos jogos entre o verdadeiro e o falso, através dos quais o ser se constitui historicamente como experiência, isto é, como podendo e devendo ser pensado. (FOUCAULT, 1984: 11-12)

Denomina o autor seu último trabalho de $A$ História $d a$ Sexualidade, composto por três volumes, nos quais quis saber o que aconteceu no ocidente para que a questão da verdade fosse relacionada ao prazer sexual. Nesse jogo, como ele mesmo afirma, mais que uma mudança temática, seu interesse pelo sujeito implica uma investigação fazendo-o recuar à Grécia clássica, pois tudo isso faz parte de uma história muito mais longa do que se imagina. Seria a história dos processos pelos quais os indivíduos se tornam sujeitos:

[...] e essas 'artes de existência', essas 'técnicas de si', perderam, sem dúvida, uma certa parte de sua importância e de sua autonomia quando, com o cristianismo, foram integradas no exercício de um poder pastoral e, mais tarde, em práticas de tipo educativo, médico ou psicológico. De qualquer modo, dever-se ia, sem dúvida, fazer e refazer a longa história dessas estéticas da existência e dessas tecnologias de si (FOUCAULT, 1984: 15). 
Larrosa (2008: 57), fundamentado nessa perspectiva, afirma que não se deve considerar as práticas pedagógicas como mero espaço de possibilidades para o desenvolvimento da autoconsciência, da autonomia ou da autodeterminação, mas como mecanismos de produção da experiência de si. No entanto, o autor salienta que se a experiência de si é histórica e culturalmente contingente, ela precisa ser também algo que deve ser transmitido e aprendido. Assim, toda cultura tem seu repertório de modos de experiência, e, por consequência, esse repertório é imposto a cada novo membro dessa cultura, ou seja, o sujeito deve aprender a ser pessoa em alguma das modalidades incluídas nesse repertório. O sujeito que estuda a língua francesa acredita estar mais bem preparado, conforme este enunciado: "[...] e também por ter um diferencial no currículo", ou considera que essa aprendizagem poderá lhe dar uma posição de destaque entre os falantes do inglês como segunda língua: "é uma língua diferente e depois todo mundo já fala inglês". Isso pode lançar luz sobre os gestos de leitura realizados do material aqui analisado, uma vez que a experiência da subjetividade discente do CELEM recebe influências de um saber transmitido e supostamente aprendido da cultura francesa. É o que as sequências enunciativas parecem manifestar.

Apropriando-se da reflexão de Larrosa, constata-se que a Educação, ao mesmo tempo em que constrói e transmite uma experiência objetiva do mundo exterior, deve construir e transmitir a experiência que as pessoas têm de si mesmas e dos outros como sujeitos. Trata-se, portanto, de produzir e de mediar certas formas de subjetivação, como sugerem, por exemplo, as questões propostas aos sujeitos da educação, as quais exigiram respostas em que esses sujeitos pudessem olhar para si. Dois enunciados são emblemáticos dessa representação:

E8: “[...] como brasileira me sinto equiparada culturalmente a qualquer país, já que para mim o que deve ser levado em conta não é a cultura de um país, mas sim como cada pessoa representa e se interessa por sua cultura”. 
E10: “[...]. Eu como brasileiro me vejo em desvantagem porque aqui as pessoas não são educadas como lá, não têm acesso à escola, nossa economia não é como a deles, lá os cidadãos são respeitados”.

Tanto nos dizeres de E8 quanto nos dizeres de E10 os sujeitos afirmam sua identidade de brasileiros ("como brasileira", "Eu como brasileiro”). Olham para si, numa atitude de pertencimento a uma dada cultura, ao mesmo tempo em que buscam se reconhecer no seu outro (o outro da cultura francesa).

A escola é um espaço onde, cotidianamente, os processos de subjetivação têm lugar e exercem uma eficácia sobre o ser-si, ora como técnica de dominação para determinar e controlar comportamentos alheios ora como prática de autogoverno. Essa forma institucional de governo de si e dos outros incide sobre o imaginário que o estudante de língua francesa tem da França. Sendo um sujeito sujeitado aos saberes que nesse espaço circulam, a experiência da sua subjetividade como discente se constitui entre mitos e práticas pedagógicas discursivas e não discursivas.

\section{Heterotopia e Subjetividade}

Apreender como se dá a formação histórica da subjetividade é imprescindível para o próximo passo, a saber, o momento em que se agrega às análises até aqui esboçadas o conceito de heterotopia, entendido, neste texto, como "o lugar outro" construído pelo estudante de língua francesa do CELEM.

Esse conceito aparece pela primeira vez no prefácio de $A s$ palavras e as coisas, obra na qual Foucault (1966/2000) explica que a ideia desse conceito lhe veio de um texto de Jorge Luis Borges que cita uma enciclopédia chinesa. Ainda em 1966, no artigo "La pensée du dehors" (O pensamento do fora), onde o termo também aparece, o autor expressa uma preocupação com a questão do espaço, mais precisamente do espaço literário. Assim, ele pensa 
um "fora” em relação à linguagem e ao sujeito. Finalmente, um terceiro texto, "Des espaces autres" (Espaços outros), resultado de uma conferência sobre estudos de Arquitetura em 1967 na Tunísia, porém publicado somente em 1984, após autorização do autor, no qual ele retoma as ideias dos outros dois, exprimindo-as como segue:

Há, inicialmente, as utopias. As utopias são os posicionamentos sem lugar real. São posicionamentos que mantêm com o espaço real da sociedade uma relação geral de analogia direta ou inversa. É a própria sociedade aperfeiçoada ou é o inverso da sociedade mas, de qualquer forma, essas utopias são espaços que fundamentalmente são essencialmente irreais. Há, igualmente, e isso provavelmente em qualquer cultura, em qualquer civilização, lugares reais, lugares efetivos, lugares que são delineados na própria instituição da sociedade, e que são espécies de contraposicionamentos, espécies de utopias efetivamente realizadas nas quais os posicionamentos reais, todos os outros posicionamentos reais que se podem encontrar no interior da cultura estão ao mesmo tempo representados, contestados e invertidos, espécies de lugares que estão fora de todos os lugares, embora eles sejam efetivamente localizáveis. Esses lugares, por serem absolutamente diferentes de todos os posicionamentos que eles refletem e dos quais eles falam, eu os chamarei, em oposição às utopias, de heterotopias (Foucault, 2006: 414-415).

Salienta-se, no entanto, que Foucault insere o termo no âmbito da literatura, pois, segundo ele, a literatura seria uma via de acesso entre a linguagem e o sujeito. A noção de espaço deve ser pensada, postula o filósofo, como o que nos é oferecido sob forma de relações de posicionamentos. Para explicitar essas relações, afirma que no espaço contemporâneo nossa vida ainda é regida por uma série de oposições, tais como o espaço público e o privado, o espaço cultural e o espaço útil, o familiar e o social, o de lazer e o de trabalho.

Há, segundo o autor, dois tipos de espaço: o das utopias, representado pelos posicionamentos sem lugar real e o das heterotopias, visto como contra-posicionamentos ou espaço das utopias realizadas. A metáfora do espelho exemplificaria essas noções, já que ele é uma utopia, pois um lugar sem lugar: o sujeito se vê "lá” onde ele 
não está. Em contrapartida, é também uma heterotopia, pois existe concretamente, mas, nesse caso, o sujeito, ao se ver "lá" no espelho, observa-se ausente no lugar em que ele realmente se encontra.

A articulação da noção de heterotopia com a de subjetividade do estudante de francês permitiu observar uma estreita relação entre o efeito da representação nacional francesa corrente nos discursos dos alunos e o lugar representado nesses discursos. Há o deslocamento de uma França, tal qual é, para um lugar outro construído em seus discursos.

Como afirma Foucault, as heterotopias são espaços que têm uma função em relação aos outros espaços, pois são de ilusão ou de compensação:

[...] as heterotopias têm, em relação ao espaço restante, uma função. Ou elas têm o papel de criar um espaço de ilusão que denuncia como mais ilusório ainda qualquer espaço real, todos os posicionamentos no interiror dos quais a vida humana é compartimentalizada. Ou pelo contrário, criando um outro espaço, um outro espaço real, tão perfeito, tão meticuloso, tão bem-arrumado quanto o nosso é desorganizado, mal-disposto e confuso. Isso seria a heterotopia não de ilusão, mas de compensação (FOUCAULT, 2006: 420-421).

Entende-se que a representação nacional vista como uma heterotopia funciona como esse espaço "outro" de compensação, como no enunciado seguinte, em que se pode observar a construção de um espaço perfeito, quando relacionado ao espaço real em que o sujeito vive de fato, mas que seria desorganizado e confuso: "lá não tem desemprego porque é um país de primeiro mundo. As pessoas têm acesso a tudo. Eles têm um ótimo padrão de vida. Então me vejo em desigualdade”. Aludindo-se às palavras de Fernandes (2006: 283), "trata-se da manifestação de uma subjetividade sócio-histórica na forma de linguagem, que possibilita a construção dos espaços"; isto é, uma exterioridade constitutiva da subjetividade do sujeito discursivo cujos sentidos são decorrentes da posição-sujeito delineada histórica e culturalmente. 


\section{Considerações finais}

Espera-se que as reflexões elencadas neste texto possam despertar o interesse em todo aquele que, de uma forma ou de outra, se encontra envolvido com questões de subjetividade quando esta é, como se sabe, constituída no e pelo discurso. Há, portanto, como se observou, uma relação intrínseca entre a representação nacional francesa e a subjetividade do estudante de francês do CELEM. Nessa experiência de si, a partir das questões propostas aos alunos, percebeu-se o encantamento do sujeito pela outra cultura. A representação apreendida, nesse contexto, como heterotopia, funciona como o espaço outro de compensação, já que eles construíram em seus discursos uma utopia cuja concretização só é possível se realizada nesse espaço outro, real e perfeito manifestado em seus enunciados. As utopias são marcadas pela conotação do impossível, logo nasce o desejo de criar um espaço outro, libertário. Pode-se, talvez, falar em heterotopia do "eu", quando sua identidade é transitória, isto é, oscila entre seu espaço real e o espaço outro.

O principal objetivo dessas reflexões, mais que verificar os efeitos da representação nacional francesa sobre o estudante de francês, foi lançar uma abertura para futuras discussões acerca das representações culturais, uma vez que se observou que elas não somente integram e constituem a subjetividade como podem criar um outro de si mesmo.

Enviado em: fevereiro de 2011
Aceito em: maio de 2011
plnavarro@uol.com.br
andrea.zingara@hotmail.com

\section{Referências bibliográficas}

Bauman, Z. Identidade - Entrevista a Benedetto Vecchi. Trad. Carlos Alberto Medeiros. Rio de Janeiro: Jorge Zahar Editor, 2005.

Davallon, J. A imagem, uma arte de memória? In: Achard, P. et al. Papel da memória. Campinas-SP: Pontes, 1999, p. 23-38. 
Dosse, F. A história à prova do tempo: da história em migalhas ao resgate do sentido. Trad. Ivone Castilho Benedetti. São Paulo: Editora UNESP, 2001.

Fernandes, C.A. Heterotopia e subjetividade nos "Becos de Goiás". In: Navarro, P. (Org). Estudos do Texto e do Discurso: mapeando conceitos e Métodos. São Carlos: Claraluz, 2006, p. 279-286.

Foucault, M. Microfísica do Poder. Trad. Roberto Machado. Rio de Janeiro: Edições Graal, 1979.

. História da sexualidade 2: o uso dos prazeres. Trad. Maria Thereza da Costa Albuquerque. Rio de Janeiro: Edições Graal, 1984.

. A arqueologia do saber. Trad. Luiz Felipe Baeta Neves. 5. ed. Rio de Janeiro: Forense Universitária, 1997.

. As palavras e as coisas. Uma arqueologia das ciências humanas. Tradução Salma Tannus Muchail. 8. ed. (coleção tópicos). São Paulo: Martins Fontes, 2000.

Retornar à história. In: Motta, M. B. (Org). Michel Foucault: Arqueologia das ciências e história dos sistemas de pensamento. Tradução Elisa Monteiro. 2. ed. Rio de Janeiro: Forense Universitária, 2005. (Ditos \& Escritos. v. II), p. 282-295.

. Outros Espaços. In: Motta, M. B. (Org). Michel Foucault Estética: Literatura e pintura, música e cinema. Tradução Inês Autran Dourado Barbosa. 2. ed. Rio de Janeiro: Forense Universitária, 2006. (Ditos \& Escritos. v. III), p. 411-422.

Gore, J. M. Foucault e Educação: fascinantes desafios. In: Silva, T. T. (Org.). O Sujeito da Educação: estudos foucaultianos. 6. ed. - Petrópolis, RJ: Vozes, 2008, p. 9-20.

Larrosa, J. Tecnologias do Eu e Educação. In: Silva, T. T. (Org.). O Sujeito da Educação: estudos foucaultianos. 6. ed. - Petrópolis, RJ: Vozes, 2008, p. 35-86. Le GOFF, J. A história nova. Trad. Eduardo Brandão. 4. ed. - São Paulo: Martins Fontes, 1998.

Navarro, P. Mídia e Identidade: o novo homem e a nova mulher entre as imagens fragmentadas e discursos "líquidos". In: Navarro, P. (Org.). O discurso nos domínios da linguagem e da história. São Carlos: Claraluz, 2008a, p. 89-100.

Discurso, História e Memória: Contribuições de Michel Foucault ao estudo da mídia. In: Tasso, I. (Org.). Estudos do texto e do discurso. Interfaces entre língua (gens), identidade e memória. São Carlos: Claraluz, 2008b, p. 59-74. 